Rethinking Marxism

\title{
On Streaming-Media Platforms, Their Audiences, and Public Life
}

\section{Aras Özgün \& Andreas Treske}

To cite this article: Aras Özgün \& Andreas Treske (2021) On Streaming-Media Platforms, Their Audiences, and Public Life, Rethinking Marxism, 33:2, 304-323, DOI: 10.1080/08935696.2021.1893090

To link to this article: https://doi.org/10.1080/08935696.2021.1893090

\section{Published online: 10 May 2021.}

Submit your article to this journal $\square$

Џll Article views: 515

Q View related articles $๘$

View Crossmark data $₫$ 


\title{
On Streaming-Media Platforms, Their Audiences, and Public Life
}

\author{
Aras Özgün and Andreas Treske
}

Over the past decade, streaming-media platforms have emerged as new and natively digital forms of content delivery. For the audience, streaming-media platforms appear as the new way of watching TV or a new kind of film distribution at the outset. Yet they radically transform the spatial and temporal settings of audience activity, introducing an algorithmically modulated logic of programming that we provisionally call microcasting and changing the way we relate to entertainment content in general. This essay critically evaluates how streaming-media platforms restructure the temporal, spatial, and relational dynamics of audience activity and strip off its collective essence. It discusses this new technological form's actual and potential effects on public life by referring to certain foundational concepts from television, audience, and film studies.

Key Words: Algorithmic Regulation, Audience, New Media, Platform Capitalism, Public Sphere

\section{Streaming-Media Platforms in the Context of Platform Capitalism}

The transformation of communication technologies in the past three decades has imposed upon us the reappraisal of both components of the term mass media by altering the temporal, spatial, and linguistic settings of information flows-and the media and public life sustained through such information flows-which had been characterized as composing a mass when the term was coined around the mid-twentieth century. Streaming-media platforms, which have become increasingly dominant forms and channels of media consumption over the past years, appear to be another phase of this transformation. This essay intends to examine how this new technological form restructures the temporal, spatial, and modal/relational dynamics of audience activity (the collective act of relating to, watching, and processing informational content) and to discuss its actual and potential effects on public life by referring to certain foundational concepts in television studies, audience studies, and film studies.

Streaming-media platforms have emerged and now operate under the conditions of a new economic modality that Nick Srnicek (2016) has labeled platform 
capitalism. This new economic modality has resulted in the domination of media and entertainment industries by businesses that provide various forms of media products and services together with a variety of other services through algorithmically regulated marketing processes. Some of these platforms (such as Google, Amazon, and Apple) offer diverse forms of entertainment products (music, film, TV programs, games, applications, social-media services) along with a variety of other products and services, whereas others (such as Netflix, Hulu, and YouTube) focus solely on providing entertainment products in a variety of narrative forms and styles that can be accessed online via computer screens and modern TV sets as well as on mobile devices.

In platform capitalism's economic context, the transformation of audience activity that streaming-media platforms effectuate is twofold. On one layer, streamingmedia platforms radically transform the spatial and temporal settings of audience activity, as we will discuss at length below. Through mobile-media technologies, viewers can watch whatever content they like anywhere and anytime. Yet the liberation of viewership from its spatial and temporal constraints also brings the erosion of its collective dimension since such spatial and temporal limits provided the social contexts that once made the audience activity a shared one. In this sense, streaming-media technology brings the fragmentation of audienceswhich started as a tendency fueled by marketing initiatives and the development of cable and satellite TV networks in the past decades - to the individual level. On another layer, the formulation of whatever content the audience likes-the almost individually customized marketing of the content-transforms what we used to call programming in television into (or rather replaces it with) what we may provisionally label as microcasting. Streaming-media platforms introduce algorithmic marketing techniques that paint now individualized audience activities with a liberating facade of personalized content delivery and pseudo interactivity. Yet the immediate effect of such pseudo interactivity is not only the concealment of the sophisticated marketing techniques involved; algorithmically personalized content delivery (that is, algorithmic formulation and presentation of what we may like based on the data available to the platform) also acts as a filter that sieves what we are already predisposed to watching and eventually sterilizes the content we are exposed to. In this second layer, the sterilization of information and narratives as such under the economic logic of the platform results in the further privatization of audience activity, narrowing the publicness of the information flows and diminishing the public sphere as we know it.

Therefore, under the all-inclusive and unifying commercial logic of the platform-in terms of narratives and their audiences, under its promise to become the common ground for everyone and every taste-we find the dissolution of the audience and of the collective form that term once necessarily referred to, the publics. In this respect, in order to evaluate the social impacts of streaming-media platforms in a political context, we first have to consider how they 
structure a new type of audience activity and how they transform the traditional modes of watching and relating to narratives.

\section{The Emergence of Streaming Media and the Rise of Algorithmic Regulation}

Over the past decade, streaming-media platforms have emerged as new and natively digital forms of content delivery. Although all traditional forms of audiovisual content (along with new interactive forms) are now being streamed online, entertainment media is increasingly being serviced through streamingmedia platforms while news media remains mostly watched on legacy TV sets on broadcast and cable channels, for practical and habitual reasons we will discuss below. According to recent statistics, streaming-media platform subscription rates increased to 69 percent in 2019 (from Io percent in 2009), surpassing the U.S. cable and satellite TV subscription rate at 65 percent (Brantner 2019). This trend is not specific to the United States: according to Motion Picture Association of America (MPAA) statistics, streaming-media subscriptions have surpassed cable TV subscriptions globally, increasing by 27 percent since 20I7; through such rapid growth, streaming-media platforms have become the dominant distribution form in the media and entertainment industry, which is now a \$Ioo billion industry globally, growing in scale by 9 percent since 2017 (Liptak 2019). Although we don't have the exact statistical data yet, the ongoing crises due to the pandemic at the moment of writing this essay seem to have immensely accelerated streaming-media platforms' market penetration. While the global film-release schedule has been upended and the advertising revenues of traditional TV channels have declined steeply due to the severe economic effects of the pandemic (Waterson and Sweeney 2020), Netflix's soaring share prices reflect the growth of streaming-media viewership over the same period (Duprey 2020).

Among others, Netflix represents a highly refined streaming-media-platform model, offering an all-inclusive subscription service in which the users/audience can choose what to watch from among the available options just like in traditional broadcast/cable TV entertainment, whereas the business models of Amazon Prime and Hulu rely on pay-per-view offerings in addition to their basic subscription content. Netflix dominates the streaming-video market by far, controlling 87 percent of the U.S. market while Amazon Prime Video and Hulu hold 52 percent and 42 percent shares, respectively (Neiger 2019). Netflix is not only globally available (except in mainland China and in Syria, North Korea, and Crimea due to U.S. sanctions) but also peculiarly local in its programming, supporting twenty-three different languages with its user interface and customer relations, and foregrounding regional productions beside its international repertoire. As such, approximately 37 percent of global internet users are believed to watch Netflix (Watson 20I9a). 
Netflix also emphasizes, both in its operation and publicity, the distinguishing feature and essential power that separates streaming-media platforms from broadcast and cable TV as technological forms: the algorithmic regulation of its service, which enables it to offer custom programming to individual users according to their individual tastes. In 2006, when it was a mail-order DVD-rental business and even before it launched its first instant-streaming service in 2007, Netflix announced the Netflix Prize: a \$I million prize for an algorithm that would improve the Cinematch algorithm that Netflix had been using in its recommendation engine for its DVD subscribers. Generating much publicity in the tech world, the prize was finally awarded in 2009 to the programmer team BellKor's Pragmatic Chaos (Buskirk 2009). Yet Netflix announced in 2012 that the winning algorithm had not been and would never be implemented; the streaming-video platform Netflix had moved to starting in 2010 had been generating a large quantity of detailed and minute data about its subscribers' preferences, and the costly implementation of the new algorithm was not needed (Johnston 2012). By switching to streaming-media distribution, Netflix did not need to predict its customers' choices anymore; their customers' watching experience had become entirely transparent, and they now "knew" their audience members' choices and had the chance to guide users' predispositions through an interface that implied interactivity. As Netflix's operation and publicity has crystalized, the algorithmic regulation of its program flow, masked behind an interactive menu, has become a constitutive element for streaming-media platforms, changing the business of "media distribution" in a profound way.

\section{The Spatial and Temporal Transformation of Audience Activity}

For the audience, at the outset, streaming-media platforms appear as the new way of watching TV or a new kind of film distribution. The media content these platforms deliver appears to be the same as what we used to watch on TV or at the movie theater. In fact, nowadays, major streaming-media platforms provide us not only with archives of television and cinema classics but also with newly released serials and movies-in some cases as soon as the serial programs are broadcast on traditional television or the films open in movie theaters (Amazon) - along with original content of the same sorts, produced by the streaming-media platforms themselves (Amazon, Netflix, Hulu, HBO, CBS All Access, Apple+).

While major streaming-media platforms compete to capture the pulse of the general public with massive investments in mainstream content, minor platforms are also starting to appear for niche audiences in this growing market, just like special-interest channels on cable TV; for example, Warner Media's DC Universe offers programming for comics fans, MUBI offers arthouse films just like an arthouse movie theater, and Criterion Channel offers cinema classics that the video distributor has amassed over the decades. Beside these global streaming-media 
platforms, we also observe the rapid emergence of local platforms catering to certain culturally or linguistically framed media markets, such as BluTV, which offers distinctly Middle Eastern programming with Turkish and Arabic interface options.

Thus, while they have slowly replaced television and movie theaters, streamingmedia platforms have appeared as a combination of both, conveniently delivered together on audiences' screens. At the same time, although the narrative forms that reach audiences through streaming appear to be the same or similar, the settings and the nature of the resulting audience activity are profoundly different from the audience activity of television broadcasting and cinema screening. Streaming-media platforms and the media-consumption patterns they introduce depart from the traditional notion of "audience activity" across two layers.

On the first and most important layer, streaming media transforms the temporal and spatial settings of audience activity. Although we perceive it as some other form of TV watching (since the activity formally resembles it by taking place before a screen), the settings of audience activity in the streaming format are different from TV: this activity doesn't necessarily take place in the living room and, in fact, as Gerard Goggin (2014) points out, it doesn't even necessarily take place in front of the TV screen. Alongside traditional TV sets, individual household members can stream the content of their choice on their individual computers, laptops, tablets, smartphones, game consoles, and mobile devices (Treske 2015). As such, streaming-media spectatorship substantially alters the spatial organization from that of watching the television.

Traditional television watching's spatial organization had two dimensions: the TV screen materialized before the audience as a visual/perceptual space and, at the same time, the TV set constructed a social space around itself-whether at home, in the middle of the living room, or in a public setting, at the pub or in the waiting room. As a visual space, the TV screen was a window that connected viewers to many distant places in the world simultaneously (Weber 1996, II7-I8). Within television's particular representational dynamics, which constantly dissect the continuity of corporeal spaces and reassemble them virtually, ${ }^{1}$ the TV screen appeared to be a perfectly heterotopic space-a "counter site ... in which the real sites, all the other real sites that can be found within the culture, are simultaneously represented, contested, and inverted" (Foucault 1986, 24). Television watching's mode of perception resembled monitoring, visually accessing events that took place simultaneously in such disparate locations, characterized as zapping between channels and programs; Cavell (1986) emphasizes this monitoring of a there (or an any-space-whatever, in Deleuze's terms) as "the material basis of television" and points out that such monitoring involves not only the viewing of live events/ shows but of all kinds of televisual content in general (205). Although the 
screen itself continues to be a heterotopic site that passes the viewer from place to place within the diegetic space of narratives, in streaming-media spectatorship, as we will discuss in more detail below, the relation to these spaces turns into a concentrated, attentive, immersive watching experience rather than a distant monitoring of events simultaneously taking place in the distance.

The diversification of viewing activity across a variety of screens and personal mobile devices, working together with the main affordance of streaming-media platforms-their seemingly personalized content delivery-results in the erosion of social space constructed around the TV set. The TV screen in audiences' living rooms loses its centrality for gathering the family around; now household members can watch the streaming content they like on their own, individually, around the house or elsewhere. TV screens in public spaces (such as pubs, waiting rooms, and airport terminals) also lose their gravitational force in contesting for audience attention and are reduced to almost decorative objects. The focal point of audience attention becomes mobile devices, which offer a new social space that now materializes on the surface of each individual screen and in the connections between these mobile devices, or otherwise takes individuals back to the familiar diegetic space of narrative while waiting alone in public.

These devices practically bring with them the temporal and spatial individualization of spectatorship, which immediately affects the social organization of time. The program flow of broadcast television had been structured according to the everyday activities of family members, with the notion of television accompanying the household in its domestic life throughout the day: weekdays started with the morning news, continued with women's magazine programs after husbands left for work, then news at lunch time, afternoon magazines, children's programs when they returned from school, the evening news when husbands came back from work, prime time for the whole family after dinner, and late-night programs after children went to sleep. Besides these regular, repetitive consecutive sequences, the TV schedule also reproduced the social-time regime of public life in its weekend and holiday programs and responded to important public events (Williams 1974). Programming in the TV industry referred not only to the production of the content but also to the scheduling of the various genres in accordance with the social schedules of different audience segments. Williams referred to the overlapping of televisual programming with social time as "planned flow" and described this as "the defining characteristic of broadcasting, simultaneously as a technology and as a cultural form" (86). This planned flow regulated individual social subjects' everyday schedules and incorporated their activities into a collectively experienced social time.

Streaming-media platforms, in comparison, deliver their programs to individual users' mobile screens not only wherever they are but also whenever they want. Under these circumstances, streaming-media spectatorship as an activity becomes completely detached from or minimally affected by social time. ${ }^{2}$ Thus, scheduling 
ceases to be a concern for these platforms, and the production and curation of content, which is now regulated by algorithmic assessments, takes precedence.

\section{Microcasting, Binge Watching, and the Transformation of Narrative Forms}

On another layer, streaming introduces what we may provisionally call microcasting - an almost individually customized form of content delivery at the practical level, further than the "narrowcasting" introduced by cable/satellite TV in the previous decades. Streaming-media spectators not only watch wherever they are, whenever they want, but also watch whatever they choose. In effect, streamingmedia platforms bring the fragmentation of the audience to the very level of the individual spectator. Past television studies showed that audience activity has been shaped by and has reflected power relations in the domestic sphere, and was previously dominated by men as the heads of households (Morley I988). In fact, women's and children's programs found space on the daily schedule of broadcast TV only at times men were supposed to be away from home (Ang 1996). Therefore, the individualization of the audience that we describe above can be perceived to have an emancipatory effect; streaming media spreads audience activity around the house(hold) and frees it from the domination of men. According to Lynn Schofield Clark (20I4), this creates a setting that enables "minor" choices within the household (choices made by women and children) to be effective in demanding content. In fact, Netflix's streaming platform anticipates such individualization from the very beginning and gives two or four different user accounts per every subscription at different price ranges when signing up, so that every household member can have a separate playlist with likes and choices individually registered.

Notwithstanding its composition by the very same people, the very same mass of "viewers," we would like to underline that the streaming-media audience is not just a "fragmented" version of the TV audience but is an entirely different one. Netflix's programming itself attests to such a transformed notion of the audience. It is significant that the constitutive formats of traditional broadcast TV programming (such as game shows, reality TV, news, talk shows, variety shows, sports, and cultural coverage) are not the most important assets on Netflix. Only culturally or

2. In this context, we also have to consider the evident transformation of social time under postFordist production regimes and the ways post-Fordist capitalism restructures the temporality of work and labor processes. The detachment of audience activity from social time through streaming-media platforms occurs in tandem with various forms of precarious labor, outsourcing, freelancing, and remote working practices that transgress 9-to-5 working hours and blur the distinction between leisure time and work time. In this respect, it is possible to think that streaming-media platforms fulfill the leisure time of social subjects who no longer conduct their lives according to a generally observed social-time regime. 
historically significant shows of these types are presented within its repertoire, in a rather retrospective, curatorial manner. These types of shows once provided the liveness of broadcast TV, and the "live broadcast" has been the essential characteristic of televisuality. In contrast, Netflix's programming is mostly geared toward narrative formats, with serials and films from every genre, and toward specialinterest documentaries. Except for the few instances of anticipating forthcoming episodes or seasons, the content on Netflix is timeless, or at least time divorced. ${ }^{3}$ Live TV programming finds its place in Netflix's scheduling only when it leaves its liveness behind, when it becomes a part of the past, or timeless, and belongs to a historical/cultural narrative. For streaming platforms like Netflix, the definitive aspect of audience activity is no longer "watching what happens in the world" as it happens, live, at the same time with the rest of the world/nation, collectively, together as a family in the living room. The liveness of the event takes a new form, and the launching of new shows and the start of new seasons become the events that construct temporality in that global depth of time upon which streamingmedia platforms operate.

Television's liveness was its constitutive attribute, the specific signifying practice that provided its ontological reference, its adherence to the real (Feuer 1983). Of course, such adherence to the real was rather an ideological effect, since its seemingly uninterrupted direct transmission of events in present time was permeated by representational devices and their ideological interventions. Still, television's potential for transmitting events live, in real time, as they happen, once made watching television as a collective social experience, a common occurrence (Carpignano 2020). In this respect, streaming-media platforms' withdrawal from liveness sets another basic condition for the individualization of their audiences.

Streaming-media platforms' detachment from liveness and exclusion of liveprogramming formats is evidently a strategical commercial choice rather than a technological limitation. Some other platforms-for example, the Amazonowned Twitch and Twitter-owned Periscope, solely rely on exploiting the livetransmission potentials of the same technological form. Also evident is that the "liveness" delegated to these "live-streaming" platforms is structured differently from that of television. Television's liveness was strategically anchored in the public significance of the event it transmitted; the common occurrence it

3. While it is true that anticipation of the release of new seasons of popular serials and shows on streaming-media platforms generates shared excitement among their viewer bases and thus has a temporal effect that points to some form of scheduling/programming, this is still different than the social scheduling/programming of broadcast TV shows and film releases since the actual watching experience happens in solitude, and since full-season releases neither sustain the temporal continuity of weekly episodes nor actually refer to the seasonal structuring of TV programming. The term "season" comes from the TV networks' fall, spring, and summer programming seasons, which determine the number of weekly episodic installments-i.e., thirteen to sixteen episodes per season. 
established was proportional to the magnitude of the different events it covered. For instance, a regional soccer match could be significant enough to be covered by a local TV station, whereas Ali knocking Foreman out in the eighth round of Rumble in the Jungle was a global event that had to be witnessed by all. The liveness of Twitch and Periscope, on the other hand, is tactically modeled after social media rather than television, capitalizing on the banality of decisively mundane and insignificant interactions between the broadcasters and their followers, which substitutes for "publicness" without attaining to it. Therefore, despite constructing a similar sense of real-time transmission, live streaming aims at facilitating a privileged, narrowly shared experience rather than a common occurrence of any scale.

Not only has the notion of live TV been depreciated, but also its serialitywhich had been another foundational aspect of televisuality-has become passé. Seriality (news programming at certain times of the day, new episodes of serials on certain days of the week, weekend programming, morning programming, etc.) created a sense of continuity and constructed a collectively experienced regime of "social time" (Cavell 1986). TV serials were the narrative form in which the temporality of narrative overlapped with that social-time regime; while the settings of the stories and the main characters extended over the seasons and sometimes overarching plotlines gradually developed, every week at the same day and time a new story with a new self-contained plot was aired. Episodic narrative was a truly modern form, introduced by magazines and daily newspapers and inherited by radio and television when broadcast media took over the power of regulating social time from print media. It sat on the cutting edge of storytelling as a craft: the impossible task of blending difference and repetition, familiarity and newness, continuity and novelty within the same text, within those forty minutes.

What we understand from business insiders is that the only reasons for streaming platforms to stick to the episodic form and presentation of traditional TV serials are a few remainders from the TV industry's past (Volpe 20I7), such as classification criteria for TV awards, following the original forms of made-for-television serials, and, perhaps, the slow-to-change habits of middle-aged viewers who grew up with the episodic serial format. The definitive form of audience activity that Netflix and other streaming-media platforms bring forth is binge watching (or just binging, as it is commonly used): a self-determined viewing activity, watching what one likes in an uninterrupted fashion, at any time one likes, independent from even spatial constraints due to the immediate availability of whole "seasons" of serials-which used to be broadcast on TV over months or on a weekly basis - or of an entire repertoire of movies in a wide spectrum of genres. Netflix built its streaming-media-distribution model on binge watching and set itself apart from linear television by introducing the full-drop release (in which all the episodes or entire seasons of TV serials are made available at once) as its publication model. Binge watching appears as a particular platform- 
sponsored hack that short-circuits the episodic seriality of TV shows, but it does in fact apply to feature films and other narrative forms as well-the platform immediately lines up what you may want to watch next in a similar genre as soon as the end credits start to roll. Within the practice of watching, the postplay function takes viewers directly to the next episode or, at the end of movies or entire serials, to a similar movie/show that the spectator may enjoy watching, rather than going back to the home page and making a deliberate choice. The skip intro function likewise allows viewers to make the narrative flow feel more seamless and uninterrupted. These interactive features ironically imply a particular form of spectatorship that relies on the insulated and continuous flow of narratives (Perks 20I4).

The continuousness of binging perverts the seriality of TV narratives not only by detaching them from the larger temporal context of the social-time regime but also from their episodic breaks and hinges. Unconstrained by the durational limits of the weekly episode format, the overarching plotlines take precedence in the narratives, diegetic settings can be constructed in detail, and multiple characters within the story can be developed to a certain depth. Episodes, in the continuous flow of binging, now function more like bookmarks, playlists, or chapters of one long narrative. In this sense, the closest relative of binging as an activity is not TV watching but reading. Like reading, binging is often a solitary, contained, and focused experience. In fact, it is precisely because of such modal similarities that watching streaming media on mobile devices can increasingly be observed as a replacement for reading books while commuting, traveling, exercising, or engaging in other kinds of leisure activities in public places.

The limited interactivity of the streaming interface imposes upon the viewer the need to immerse in and interact with the text itself, and the insulated flow of binge watching reinforces the built-in dynamics of the narratives (Treske 2013). This form of relation between the narrative and the spectator differs from that of cinema by its solitariness and continuity and from that of television by its intensity and concentration. As we mentioned above, television spectatorship mostly resembled the monitoring of content rather than closely following the flow of programs throughout the day. Television accompanied the everyday routine of social subjects in their everyday routines, both in domestic and public settings, and their attention shifted on and off from the program flow during those routines. Music television, for example, is an excellent example of television as accompaniment, remaining always on but mostly in the background while people go about their everyday chores (Kaplan 1987). The isolated and immersive experience that streaming-media platforms facilitate thus precludes one of the most important affordances that made TV an integral part of social life: its common co-occurrence.

The growing popularity of hyperdiegetic narratives on streaming-media platforms can be associated with this new form of audience activity. Hyperdiegetic narratives are different works of fiction that take place in the same narrative time and space and share or reference each other's plotlines, characters, or 
other narrative elements, such as DC's The Flash, Arrow, and Legends of Tomorrow series; AMC's Breaking Bad and Better Call Saul (streaming on Netflix); and Marvel's Jessica Jones, Daredevil, Luke Cage, Iron Fist, and The Punisher Netflix franchises. Among these, Marvel's Netflix franchises provide an excellent example of how hyperdiegesis emerges as a new narrative modality that couples with the individualized audience that we are concerned with in this essay. Although they exist in the same universe and share characters and references to each other's plotlines, each narrative belongs to a different well-established genre and appeals to the distinct audience of that genre. Yet the hyperdiegetic connections and threads among the narratives hook all of these distinct audiences into the Marvel Universe, getting them to consume genres that they would generically refrain from (Treske and Özgün 2020).

\section{The Privatization of Audience Activity: A Scheherazade for Every Shahryar}

While defining television as a decentered form of postmodern media, Ann Kaplan (1987) argues about a foundational difference between cinema spectators and TV audiences. She points to the frame that delimits the experience of the cinema spectator in a Simmelian (1994) fashion. Cinema has been framed temporally by the fixed duration of its narrative, which only lasts for so long, and spatially by the darkness of the movie theater, which surrounds the image. The never-ending flow of programs on television, on the other hand, creates a continuum that has no spatial and temporal boundaries. Cinema captures spectators by triggering their desires and offering a pleasurable dream from which viewers eventually wake up at the end of the film - to face the actuality of everyday life upon exiting the movie theater. Television, on the other hand, offers its audience plenitude: there is always something to watch-if not at that moment, then a few minutes later; if not on that channel, certainly on one of the others. For Kaplan, that insatiable desire for plenitude kept the audience watching around the clock and diverted their attentive enjoyment to the consumer products advertised in the meanwhile.

Streaming-media platforms present an amplified effect of plenitude without the advertisements in their subscription-based services. In this respect, they seemingly redeem the narrative from interruption by those consumer products that belong to everyday banality. Yet this is a deception that hides the fact that the streaming platform is itself the ultimate consumer product: one can never finish consuming it, it always has more to offer than one can ever want, regardless of how different one's desires may be, a personal Scheherazade for every Shahryar.

The illusion of interactivity sustains the semblance of difference and differentiation; we find this show or that movie on the platform, add it to our playlist, and choose to watch it whenever we want-as if those movies and shows are not 
algorithmically curated for us based on the general consumption patterns associated with our customer profile and boldly pushed onto the top of the screen toward our attention. Therefore, it seems necessary to consider streamingmedia platforms in the context of the global culture industry, as portrayed by Lash and Lury (2007): an industry whose products are indeterminate objects that seek to produce differences and differentiations rather than identities. In fact, the impetus is obvious; the platform makes viewers think that their tastes are different, that they want to hear a different story, that the story is different. Such promise of difference becomes incorporated into other cultural and aesthetic distinctions that distinguish the bourgeois lifestyle (Bourdieu 2007).

The demographic distribution of streaming-media subscription statistics clearly establishes such distinctions. In the United States, where we observe severe disparities among the income levels of demographic categories, the subscription rate of the most popular streaming-media platform, Netflix, remains 59 percent in White households (Watson 2019b), yet it is 39 percent among Black households (Umstead 2019). The subscription rates of other streaming-media platforms among the Black population gives the impression that Netflix's rate is in fact disproportionately higher (probably because of its marketing strategies, which include offering free subscriptions to T-Mobile customers en masse). For example, Amazon Prime's overall U.S. market share, which is approximately two-thirds that of Netflix, falls to I4 percent among Blacks (Umstead 2019). It is possible to consider the Amazon Prime subscription having a more direct correlation with income level since it also gives its subscribers certain privileges (such as free shipping) if they already frequently purchase Amazon's other services.

Clearly there is more empirically oriented research to do regarding the structuring of streaming-media platforms and markets, from a political-economic perspective and at a global scale. In the absence of such in-depth studies, we can still deduce the economic/class base of streaming-media subscriptions from the demographic distribution, considering the intersectionality between demographic categories and income levels. The demographic distribution is interesting and symptomatic in the context of the algorithmic regulation of streaming content and platform capitalism; it shows that algorithmic regulation favors economically privileged demographic categories and, in this sense, amplifies the existing tendencies of traditional commercial-media channels (see O'Neil 2016). Within the narrowcasting strategies of cable and satellite television, marginal and minor demographic categories or "cultural interests" could find dedicated channels (BET, Telemundo, etc.) that accordingly filled their entire programming. In contrast, while serving the broadest possible audience, streaming-media channels seemingly respond to such special demographic/cultural interests by including such programming in their rosters and leaving it to the interactive choices of the respective audiences. Yet they invest in their productions by acknowledging the economic and demographic composition of their subscribers in a precise manner, catering to their financially able subscriber base. 
Netflix, with its global reach, exemplifies such an orientation in its production and distribution choices, offering a majority of local productions along with a variety of "foreign" narratives in the countries/media markets that it serves. Beside the content it licenses to offer in each market, the local productions that Netflix produces in specific media markets constitute the "foreign" programming that it offers in other media markets, altogether establishing its "multicultural" content and outlook. For example, the Turkish TV series that Netflix produces for the Turkish market—such as The Gift and The Protector, which cater to Netflix's upwardly mobile, urban, young-professional subscriber base in Turkey, constructing the distinction of its brand/programming in Turkey's specific cultural context - are also highlighted as part of its foreign content in the United States, catering to a similar local subscriber base, the members of which are more open to watching foreign content as a result of their education level, international exposure, metropolitan cultural formation, and socially and geographically mobile lifestyle. As a result, what appears to be multicultural content at a global scale is a circulation of similar narratives stylistically designed and encoded for appealing to the "world citizens" of the new global bourgeoise. Excluded in this circulation are culturally specific, distinctly local, folksy, or artistic narratives that characterize or reflect upon public life in those "other" cultural spheres. The native cultural forms of those who cannot pass the borders likewise cannot pass through Netflix's algorithms.

\section{Reconsidering Audience, Publics, and the Public Sphere}

Both broadcast viewing and film screening were once experienced by audiences as collective activities. Broadcast TV, as a technological form, was "regional" by design, and the TV industry operated at local and national scales. Cinema, from its early inception, had operated as a form of mass entertainment/public art. The "collectiveness" of the audience activity in both of these media forms was embedded in their economy. Public (meaning, publicly owned) broadcast TV channels had to air programs that either appealed to the general public or were deemed to serve the public good in other ways (e.g., by having educational, informational, or artistic value). In private, profit-oriented broadcasting, programs were offered to the public for free, and TV stations financed their operations through the revenues that they gathered from advertisement segments shown in between programs. Thus, appealing to the general public was an economic imperative for private TV channels.

The film industry had been shaped with the same economic imperative: films had to be shown in movie theaters and watched collectively; thus, as both an art and an entertainment form at the same time, films had to appeal to the general public. The difference in scale between the general audience of broadcast TV stations and spectators in movie theaters allowed certain niches in cinema- 
special-interest films that would never have been a part of public broadcasting could be shown in movie theaters dedicated to such genres. Yet such niches still depended on the availability of corresponding public interest; one could find such special-interest movie theaters only in neighborhoods and towns with enough people who shared such special interests.

The term audience had always implied multitudes. Whatever we watched, we never watched it alone: we watched TV in our living rooms at the same time with millions of others; we watched films in dark movie theaters together with strangers. Watching had likewise never been a passive exposure; watching together implied decoding, debating, understanding, reacting, and being inspired together. Watching together (what we refer to as audience activity in this essay) turned those multitudes into "publics" that shared common concerns, ideologies, and inspirations. If print media-books, magazines, and newspapers-had been instrumental in the creation of the public sphere in the nineteenth century (Habermas 1989), modern publics had been woven together by cinema and broadcast media. The media events that Dayan and Katz (1992) smartly identified and analyzed were based on the exploitation of the collective nature of audience activity. Media events were preprogrammed coverage of extraordinary occurrences (such as the Apollo II moon landing in 1969) that broke with the banality of the daily regime of news magazines and serials, that broadcast history live on TV globally and rendered the watching masses as witnesses and as a part of that history.

Throughout modern times, in the era of mass media, from the first newspaper to the emergence of multiplex movie theaters, audience had referred to a twofold entity. It is because of this twofold reference, actually, that we can use the term audience in both singular and plural forms in the English language. On one hand, it referred to those multitudes that watched, read, and responded to the news and stories: a corporeal mass of living people, the plural form. On the other hand, it referred to an imaginary collective subject, in its singular form, whose feelings, tastes, values, and psychology (and, rarely, intellectual awareness) was the primary concern of newspaper editors, Hollywood executives, and TV producers. The audience, as much as a living public, had been the ghost in the narrative, and precognition of its unforeseeable reactions to stories was the job of editors and producers (Ang 1996).

As such, the audience was always present in the narrative as a collective being-if not diegetically, then certainly indexically, as a collective subject that is physically embodied in every person that listens, reads, or watches. Modern mass media, in its various forms, offered a shared experience to otherwise dispersed strangers who listened, watched, or read together, and this turned them into publics. Benedict Anderson (199I) points to the shared experience of reading novels and the newspapers-not only in the sense of being exposed to the same stories but also of being a part of a temporality sustained by the print media-as among the origins of the nation as an imagined community. The making of a public out of multitudes was perceived as such a crucial aspect of modern governmentality 
that mass media was considered a prerequisite for nation building, particularly in the context of the modernization of Third World countries (see Rugh 2004). Throughout modern times, public opinion and the lowest common denominator, that sweet spot of public opinion where every taste and value meet, had been the curse of liberal democracies that actually somehow made it work. The individualization of the audience thus has to be considered in this political context, too, as the dissolution of the publics as we knew them. The platform-the difference engine that constantly detects, cultivates, and manufactures differentials and turns them into flows of demand and supply-replaces the curse that it lifts with another one: "I" is now always an algorithmically categorized other.

For the producers of streaming platforms, audience is no longer either imaginary or collective; the audience has been fragmented into its atoms in the way that every atom has become identifiable and explicable. Chris Marker ([1983] 2007) claims in Sans Soleil that, in the specific cultural context of Japanese TV, the more you watch "the more you feel it watches you." In the context of streaming-media platforms, this ceases to be an irony. The producers of the streaming platforms know their spectators individually and feel their pulse with an unprecedented precision. They know what we watch, how we watch, when we watch, what we do before and after we watch, and our other mundane activities-well beyond what we watch. Producers now only produce what they definitely know particular individual audience members (and how many in total) will watch. We, the individuals formerly composing the audience, do not buy this or that TV show or film; we subscribe to the streaming platform, knowing that it knows and delivers what we are interested in watching. Unlike previous mediadistribution systems, Netflix does not intend to sell individual shows/products. Instead, it aims to sell a service, an experience that becomes a part of a certain lifestyle, a virtual shopping mall of narratives in which a broad range of individuals belonging to a certain socioeconomic demographic (urban, financially able, upwardly mobile, educated young professionals) with somehow varying tastes can find what they consider "their niche" for enjoyment.

What does the semblance of public that streaming-media networks' audiences create tell us about the public life of what we can now rightfully call platform societies in general? In the past two decades, emerging social-media platforms have been celebrated as a means of connecting people who are geographically separated (and who are even stranger to each other without such connection) and thus as a means of commoning, community building, and creating publics. Yet those commonalities, connections, and communities have been built and regulated by algorithms designed with profit-maximization incentives (see Einstein 2016). Just as streaming-media platforms sterilize our leisure time by providing us only with what we are predisposed to watch, social-media platforms sterilize our connections with the outside world; we selectively friend people whom we already know, whom we are familiar with, or whom we may like according to Facebook's (or some other social-media network's) algorithms (see Pariser 20II). 
Despite all the problems we can attribute to what the term public has represented throughout modernity and how the modern public sphere has worked (Özgün 20I0), these terms have never referred to a sterile and homogenous mass: although it has never been all-inclusive, "public" has discreetly signified the others. Public (ness) has meant brushing shoulders with strangers, encountering unfamiliar and sometimes unpleasant stories, and negotiating and learning from differences. The collectiveness of audience activity in modern mass media, in the movie theater and in front of the TV screen, has virtually and practically imposed constant exposure to differences and emergencies, whereas streaming-media viewership is not only a solitary activity but also an isolated one, sterilized by a platforms' algorithmic controls. The past differences and emergencies of public life are substituted with seemingly endless options and novelties offered by a platform seemingly geared toward the individual choices of its users.

It thus seems possible to us to consider the current rise of populist authoritarianisms, with all their negation of others and differences, as inevitable consequences of the sterile public life of platform societies. Sherman (2016, I83) rightfully associates the fragmentation and splintering of audiences (in profit-oriented traditional broadcast media as well as in the algorithmically regulated social-media sphere) with the privatization of the cultural commons, led by the commodification of communications, noting that, as a consequence, "Each imagined community grows smaller and more homogeneous, while the members of different pseudo-commons become incomprehensible to one other."

The notion of the "public sphere" once provided the necessary theoretical passage between mass communications and politics, and dominated the intersection of critical media studies and the political sciences, in its formulation by Habermas (1989), with reference to the emergence of the "reading public" after the development of the printing press. According to Habermas's historical narrative, the emergence of the public sphere was a social effect of mass media; the widespread circulation of information through print media generated public debates in literary salons and coffee houses on matters related to public life and "people's public use of their reason" (27). Habermas's notion, while providing a passage between media and politics, also demarcated the separation of these as two different domains in Marxian analysis. Politics was the sphere of criticalrational debate and deliberation, of the formation of "public opinion," whereas media was the "precondition" for such critical-rational debate. The "political aspects" of media itself, following this demarcation, were then left to critical analysis of the economic structuring of media industries, on one hand, and critical analysis of informational content, on the other-that is, the formation of meaning, the cultural context/circulation of codes, and the field of semiology in general.

But the picture we describe above complicates both registers of critical analysis. Regarding the first register, the economic structuring of platform capitalism relies on the capitalization of social flows of information and tightly incorporates these 
within other forms and sources of economic production. Current works on the political economy of digital media networks-such as Azhar's (202I) discussion on the political economy of pay-per-click business models and Sherman's (2016) analysis of the privatization and fragmentation of the attention economy, mentioned above-reflect upon these complications. Regarding the second register, the blurring of the distinction between "mainstream" and "alternative" representational regimes imposes challenges for identifying the referential contexts of the discursive practices we encounter today. Streaming-media platforms offer mainstream and hegemonic entertainment content together with marginal and alternative narrative forms and styles, mixing different representational regimes together or, in the case of what algorithmically prefigured user profiles suggest, even by foregrounding alternative forms and styles-in other words, by prioritizing alternative representational regimes over hegemonic ones.

For example, Netflix's home screen offers a distinct category of narratives titled "Featuring a Strong Female Lead" for its users whose watching habits display a tendency toward appreciating such narratives according to the platform's algorithmic assessment. The presence of such a category would have been a progressive move in traditional media outlets since the stories of powerful women would provide a positive identification mechanism for vulnerable women and would contribute to the empowerment of women in general. However, in the particular context of Netflix's marketing, narratives of this kind are offered to its subscribers who already possess a certain degree of economic and social power in their lives and who already indicate ideological dispositions toward watching such narratives. In this case, having the choice and the incentive to watch the stories of strong women becomes a part of lifestyle-consumption patterns that signify a class distinction, serving to sustain existing social-power relations rather than intervening within them.

Thus, the disintegration of publics that we encounter today, which has become crystalized in the audience activity of streaming-media platforms but also remains an inherent feature of social-media platforms in general, eventually brings the long overdue depreciation of the notion of the public sphere as such. In his criticism of the Habermasian conceptualization, Carpignano (1999) suggests that media should be studied as the "social relation of communication" itself rather than as a technology or institution that regulates communication: "The public sphere could be analyzed not only from the point of view of the formation and development of public discourse and actions, but also as the location where the material articulations, the technological mediations of social communication, take place. In sum, adopting this kind of perspective would mean investigating not only what is public in the public sphere, but also how publicity is materially constituted."

We mentioned that streaming-media platforms-in regard to the narrative forms and the audience activity they bring about-replace television and cinema by combining them together in streaming media as a new media form. However, while 
following Carpignano's proposition and conceiving this form as a new site of material articulations and technological mediations of social communication, it may be as relevant to consider how this form substitutes for the local bookstore or the DVD rental on the corner, with no need to talk to the guy at the counter who always disagrees with your choices, to encounter your chatty neighbors strolling around the aisles, or to navigate the noisy, crowded street you have to walk to get there-in other words, without the actual world and the noise of life that surrounds the narrative. The atomization of audiences and the sterilization of audience activity that this essay is concerned with in the context of streaming-media platforms are imposed not by the technology itself but rather by the commercial logic inherent to platform capitalism, which can be extended (perhaps with slightly different dynamics) to all the communication sites that such platforms establish, starting from the domain of social media. Such inherently antisocial logic, unfortunately, appears before us as the logic of our new social relation of communication.

\section{References}

Anderson, B. 1991. Imagined Communities: Reflections on the Origin and Spread of Nationalism. London: Verso.

Ang, I. 1996. Living Room Wars: Rethinking Media Audiences for a Postmodern World. New York: Routledge.

Azhar, S. 202I. "Consumption, Capital, and Class in Digital Space: The Political Economy of Pay-per-Click Business Models.” Rethinking Marxism 33 (2): 196-216.

Brantner, C. 2019. "More Americans Now Pay for Streaming Services than Cable TV." Forbes, 20 March. https://www.forbes.com/sites/chrisbrantner/2019/03/20/americansnow-pay-more-for-streaming-services-than-cable-tv/\#496aI33fcdd2.

Bourdieu, P. 2007. Distinction: A Social Critique of the Judgement of Taste. Trans. R. Nice. Cambridge, Mass.: Harvard University Press.

Carpignano, P. 1999. "The Shape of the Sphere: The Public Sphere and the Materiality of Communication." Constellations 6 (2): 177-89.

- 2020. "The Live." Televisuality Lectures. Accessed 30 December 2020. https://web. archive.org/web/20041217135926/ http://www.newschool.edu/mediastudies/tv/channel6/ pager.html.

Cavell, S. 1986. "The Fact of Television." In Video Culture: A Critical Investigation, ed. J. G. Hanhardt, 192-2I8. Rochester, N.Y.: Virtual Studies Workshop.

Dayan, D., and E. Katz. 1992. Media Events: The Live Broadcasting of History. Cambridge, Mass.: Harvard University Press.

Duprey, R. 2020. "TV Viewership Is Surging During the Pandemic: Here's What People Are Watching." Motley Fool, 28 March. https://www.fool.com/investing/2020/03/28/tvviewership-surging-what-people-are-watching.aspx.

Einstein, M. 2016. Black Ops Advertising: Native Ads, Content Marketing, and the Covert World of the Digital Sell. London: OR Books.

Feuer, J. 1983. "The Concept of Live Television: Ontology as Ideology." In Regarding Television: Critical Approaches-An Anthology, ed. A. Kaplan, I2-22. Frederick, Md.: University Publications of America.

Foucault, M. 1986. "Of Other Spaces." Diacritics I6 (I): 22-7. 
Goggin, G. 20I4. "Mobile Video: Spreading Stories with Mobile Media." In The Routledge Companion to Mobile Media, ed. G. Goggin and L. Hjorth, I46-56. New York: Routledge.

Habermas, J. 1989. The Structural Transformation of the Public Sphere: An Inquiry into a Category of Bourgeois Society. Cambridge: Polity.

Johnston, C. 20I2. "Netflix Never Used Its \$I Million Algorithm Due to Engineering Costs." Wired, I2 April. https://www.wired.com/2012/04/netflix-prize-costs/.

Kaplan, E. A. 1987. Rocking around the Clock: Music Television, Postmodernism, and Consumer Culture. London: Routledge.

Lash, S., and C. Lury. 2007. Global Culture Industry: The Mediation of Things. Malden, Mass.: Polity.

Liptak, A. 2019. "The MPAA Says Streaming Video Has Surpassed Cable Subscriptions Worldwide." Verge, 2I March. https:/www.theverge.com/20I9/3/21/18275670/mpaareport-streaming-video-cable-subscription-worldwide.

Marker, C., dir. (1983) 2007. Sans Soleil. New York: Criterion Collection.

Morley, D. 1988. Family Television: Cultural Power and Domestic Leisure. London: Routlege.

Neiger, C. 2019. "Netflix's Market Share Is Shrinking, but It's Still the King of Video Streaming," Motley Fool, 27 August. https://www.fool.com/investing/2019/o8/27/netflixmarket-share-shrinking-still-streaming.aspx.

O'Neil, C. 20I6. Weapons of Math Destruction: How Big Data Increases Inequality and Threatens Democracy. New York: Crown.

Özgün, A. 20Io. “A Common Word.” Rethinking Marxism 22 (3): 374-8I.

Pariser, E. 20II. The Filter Bubble: What the Internet Is Hiding from You. New York: Penguin.

Perks, L. G. 20I4. Media Marathoning: Immersions in Morality. London: Lexington.

Rugh, W. 2004. Arab Mass Media: Newspapers, Radio, and Television in Arab Politics. Westport, Conn.: Praeger.

Schofield Clark, L. 20I4. "Mobile Media in the Emotional and Moral Economies of the Household." In The Routledge Companion to Mobile Media, ed. G. Goggin and L. Hjorth, 320-32. New York: Routledge.

Sherman, Z. 20I6. "Primitive Accumulation in the Cultural Commons." Review of Radical Political Economics 48 (I): 176-88. https://doi.org/IO.II77/04866I34I5586993.

Simmel, G. 1994. "The Picture Frame: An Aesthetic Study.” Theory, Culture E Society II (I): II-I7.

Srnicek, N. 20I6. Platform Capitalism. Cambridge, UK: Polity.

Treske, A. 2013. The Inner Life of Video Spheres. Amsterdam: Institute of Network Cultures.

- 2015. Video Theory: Online Video Aesthetics or the Afterlife of Video. Bielefeld, Germ.: Transcript Verlag.

Treske, A., and A. Özgün. 2020. "Narrative Platforms: Towards a Morphology of New Audience Activities and Narrative Forms." In Video Vortex Reader III: Inside the YouTube Decade, ed. G. Lovink and A. Treske, II7-3I. Amsterdam: Institute of Network Cultures.

Umstead, T. 2019. "African-Americans are Leaders in Media Consumption." Multichannel News, I5 September. https://www.multichannel.com/blog/african-americans-areleaders-in-media-consumption.

Van Buskirk, E. 2009. "How the Netflix Prize Was Won." Wired, 22 September. https://www. wired.com/2009/og/how-the-netflix-prize-was-won.

Volpe, A. 2017. "The One Thing That Isn't Evolving with Netflix \& Hulu's Takeover of TV." Thrillist, I6 October. https:/www.thrillist.com/entertainment/nation/netflix-episodelength-streaming-services-traditional-tv. 
Waterson, J., and M. Sweney. 2020. "Covid-I9 Leaves News and Entertainment Industries Reeling.” Guardian, I7 April. https://www.theguardian.com/media/2020/apr/I7/howcovid-I9-turned-the-uk-news-and-entertainment-industry-upside-down.

Watson, A. 2019a. "Netflix-Statistics and Facts." Statista, 27 May. https://www.statista.com/ topics/842/netflix.

- 20I9b. "Share of Adults with a Netflix Subscription in the United States as of December 2018, by Ethnicity." Statista, I7 December. https://www.statista.com/ statistics/760330/netflix-subscription-adults-usa-ethnicity.

Weber, S. 1996. Mass Mediauras: Form, Technics, Media. Stanford: Stanford University Press. Williams, R. 1974. Television: Technology and Cultural Form. London: Fontana. 